\title{
Review
}

Lawrence B. Afrin*, Mary B. Ackerley, Linda S. Bluestein, Joseph H. Brewer, Jill B. Brook, Ariana D. Buchanan, Jill R. Cuni, William P. Davey, Tania T. Dempsey, Shanda R. Dorff, Martin S. Dubravec, Alena G. Guggenheim, Kimberly J. Hindman, Bruce Hoffman, David L. Kaufman, Stephanie J. Kratzer, Theodore M. Lee, Mindy S. Marantz, Andrew J. Maxwell, Kelly K. McCann, Dwight L. McKee, Laurie Menk Otto, Laura A. Pace, Dahra D. Perkins, Laurie Radovsky, Mary S. Raleigh, Sonia A. Rapaport, Emma J. Reinhold, Mark L. Renneker, William A. Robinson, Aaron M. Roland, E. Scott Rosenbloom, Peter C. Rowe, llene S. Ruhoy, David S. Saperstein, David A. Schlosser, Jill R. Schofield, Janet E. Settle, Leonard B. Weinstock, Martina Wengenroth, Mark Westaway, Shijun Cindy Xi and Gerhard J. Molderings

\section{Diagnosis of mast cell activation syndrome: a global "consensus-2"}

https://doi.org/10.1515/dx-2020-0005

Received January 5, 2020; accepted February 15, 2020

Abstract: The concept that disease rooted principally in chronic aberrant constitutive and reactive activation of mast cells (MCs), without the gross MC neoplasia in mastocytosis, first emerged in the 1980s, but only in the last decade has recognition of "mast cell activation syndrome" (MCAS) grown significantly. Two principal proposals for diagnostic criteria have emerged. One, originally published in 2012, is labeled by its authors as a "consensus" (re-termed here as "consensus-1"). Another sizable contingent of investigators and practitioners favor a different approach (originally published in 2011, newly termed here as "consensus-2"), resembling "consensus-1" in

*Corresponding author: Lawrence B. Afrin, MD, Armonk Integrative Medicine, 3010 Westchester Avenue, Suite 404, Purchase, NY 10577, USA, Phone: +914-730-7390, Fax: +914-730-7391,

E-mail: drafrin@armonkmed.com.

https://orcid.org/0000-0003-3550-4244

Mary B. Ackerley: My Passion 4 Health, Tucson, AZ, USA, E-mail: lucid@dakotacom.net

Linda S. Bluestein: Department of Anesthesiology, Medical College of Wisconsin, Wausau, WI, USA, Email: lindabluestein@yahoo.com Joseph H. Brewer: Plaza Infectious Disease, Kansas City,

MO, USA, Email: jbrewer@plazamedicine.com

Jill B. Brook: Alaska Internal Medicine and Pediatrics, Anchorage, AK, USA, Email: jillbrook@msn.com

Ariana D. Buchanan and Theodore M. Lee: Peachtree Allergy and Asthma, Atlanta, GA, USA, Email: abuchananmd@aol.com (A.D. Buchanan); drtedlee@peachtreeallergyclinic.com (T.M. Lee) Jill R. Cuni: Division of Pediatrics, Beaver Medical Group, Banning, CA, USA, Email: jcuni@epiclp.com

William P. Davey: Department of Dermatology, University of Kentucky, Lexington, KY, USA, Email: wpdavey@gmail.com some respects but differing in others, leading to substantial differences between these proposals in the numbers of patients qualifying for diagnosis (and thus treatment). Overdiagnosis by "consensus-2" criteria has potential to be problematic, but underdiagnosis by "consensus-1" criteria seems the far larger problem given (1) increasing appreciation that MCAS is prevalent (up to $17 \%$ of the general population), and (2) most MCAS patients, regardless of illness duration prior to diagnosis, can eventually identify treatment yielding sustained improvement. We analyze these proposals (and others) and suggest that, until careful research provides more definitive answers, diagnosis by either proposal is valid, reasonable, and helpful.

Tania T. Dempsey: Armonk Integrative Medicine, Purchase, NY, USA, Email: drdempsey@armonkmed.com. https://orcid.org/0000-00025325-0412

Shanda R. Dorff: Complex Cares, LLC, Shoreview, MN, USA, Email:drdorff@complexcaresmn.com

Martin S. Dubravec: Allergy and Asthma Specialists of Cadillac, Cadillac, MI, USA, Email: biosp3@sbcglobal.net

Alena G. Guggenheim: Comprehensive Pain Center, Oregon Health and Science University, Portland, OR, USA,

Email: alena.guggenheim@gmail.com

Kimberly J. Hindman: Healing Dragon, Portland, OR, USA, Email: khindman@healingdragon.net

Bruce Hoffman: Hoffman Centre for Integrative and Functional Medicine, Calgary, Alberta, Canada,

Email: brucehoffman@hoffmancentre.ca

David L. Kaufman: Center for Complex Diseases, Mountain View, CA, USA, Email: david@centerforcomplexdiseases.com

Stephanie J. Kratzer: CHI Health St. Elizabeth, Lincoln, NE, USA, Email: skratzer@stez.org 
Keywords: chronic illness; mast cell activation disease; mast cell activation syndrome; medical controversies; medically unexplained symptoms; misdiagnosis.

\section{Introduction}

The concept that a class of diseases rooted principally just in chronic aberrant constitutive and/or reactive activation of mast cells (MCs; and with only modest increases in MC numbers due to reduced apoptosis rather than the marked MC neoplasia defining the rare disorder of mastocytosis) ought to exist was first published in 1984-1991 [1-3]. The heterogeneity of the full range of such patients' clinical presentations is extreme, but symptoms/findings (typically waxing/waning and migratory) often include flushing, allergic-type issues, fatigue, dermatographism, cognitive dysfunction, irritated eyes/nose/ mouth/throat, adenitis, dyspnea, palpitations, nausea, reflux, abdominal pain, diarrhea (often alternating with constipation), interstitial cystitis, vulvovaginitis, menorrhagia, dysmenorrhea, fibromyalgia-type pain, joint hypermobility, benign growth anomalies (e.g. cysts, fibrosis, vascular anomalies, poor healing), headache, sensory

Mindy S. Marantz: Healthwell Physical Therapy Group, San Francisco, CA, USA, Email: mmarantz@healthwellpt.com Andrew J. Maxwell: Heart of the Valley Pediatric Cardiology, Pleasanton, CA, USA, Email: amaxwell@heartofthevalley.us Kelly K. McCann: The Spring Center, Costa Mesa, CA, USA, Email: kellybird28@gmail.com

Dwight L. McKee: Integrative Cancer Consulting, Aptos, CA, USA, Email:dlmckeemd@gmail.com

Laurie Menk Otto: Helfgott Research Institute, National College of Natural Medicine, Portland, OR, USA,

Email: laur.menk.otto@gmail.com

Laura A. Pace: Division of Gastroenterology, Hepatology and Nutrition, University of Utah, Salt Lake City, UT, USA,

Email: laura.pace@hsc.utah.edu

Dahra D. Perkins: Elevate Health, Portland, OR, USA,

Email: dahra.perkins@gmail.com

Laurie Radovsky: St. Paul, MN, USA, Email: laurie@drradovsky.com

Mary S. Raleigh: Restoration Healthcare, Irvine, CA, USA,

Email: sunnyraleigh@rhealthc.com

Sonia A. Rapaport: Haven Medical, Chapel Hill, NC, USA,

Email: soniarapnc@gmail.com

Emma J. Reinhold: Royal College of General Practitioners, London,

UK, Email: e.reinhold@doctors.org.uk

Mark L. Renneker and Aaron M. Roland: Department of Family

Medicine, University of California San Francisco, San Francisco,

CA, USA, Email: mark.renneker@ucsf.edu (M.L. Renneker);

doctoraaron@pacbell.net (A.M. Roland)

William A. Robinson: Division of Hematology/Oncology, University of Colorado, Denver, CO, USA, Email: william.robinson@ucdenver.edu neuropathy, dysautonomias (e.g. orthostatic hypotension, blood pressure and heart rate lability, thermal dysregulation), anxiety and mood disorders, and an assortment of metabolic/endocrinologic (e.g. thyroid) aberrancies. In 2007, the first case reports were published [4,5], followed shortly by a limited proposal for diagnostic criteria in cases where MC clonality could be identified [6]. Subsequent literature regarding this newly recognized (but of course not truly new) "mast cell activation syndrome" (MCAS) included case reports as well as formal studies (mostly relatively small scale), reviews, and various proposals for formal diagnostic criteria. Two principal such proposals emerged - the first published initially in late 2010 [7] and the second published initially in early 2011 [8]. The former proposal was adjusted by its authors and others and republished in 2012 [9], labeled by them at that time as a "consensus." However, followers of MCAS literature know there is another sizable world-wide contingent of investigators and practitioners - and patients - who feel there are significant problems with the "consensus" approach and who thus favor the alternative approach advocated by the authors of the 2011 paper, which resembles the "consensus" approach in some respects but differs in a number of other respects. An important difference between these

E. Scott Rosenbloom: Sacramento, CA, USA, Email: skiprosenbloom@gmail.com

Peter C. Rowe: Department of Pediatrics, Johns Hopkins University, Baltimore, MD, USA, Email: prowe@jhmi.edu

Ilene S. Ruhoy: Center for Healing Neurology, Seattle, WA, USA, Email: ilene@centerforhealingneurology.com

David S. Saperstein: Center for Complex Neurology, EDS and POTS, Phoenix, AZ, USA,

Email: drsaperstein@complexneurology.com

David A. Schlosser: Patient Navigator, LLC, Reston, VA, USA, Email: dschlosser@patientnavigator.com

Jill R. Schofield: Department of Internal Medicine, University of Colorado School of Medicine, Aurora, CO, USA,

Email: js@centerformultisystemdisease.com

Janet E. Settle: Department of Psychiatry, University of Colorado, Denver, CO, USA, Email: drjanetsettle@gmail.com

Leonard B. Weinstock: Department of Medicine, Washington University, St. Louis, MO, USA, Email: Iw@gidoctor.net

Martina Wengenroth: Institute of Neuroradiology, University Hospital Lübeck, Lübeck, Germany,

Email: martina.wengenroth@googlemail.com

Mark Westaway: Westaway Medical, Brisbane, Queensland, Australia, Email: drmarkwestaway@gmail.com

Shijun Cindy Xi: Section of Allergy and Immunology, Keck School of Medicine, University of Southern California, Los Angeles, CA, USA, Email: xicindy@gmail.com

Gerhard J. Molderings: Institute of Human Genetics, University Hospital of Bonn, Bonn, Germany, Email: molderings@ uni-bonn.de 
proposals is the number of patients who would qualify for an MCAS diagnosis. Underdiagnosis by inappropriately restrictive criteria is dangerous given (1) increasing evidence of substantial prevalence of MCAS (various publications, based on varying amounts of data, have provided estimates ranging from "rare" [10] to as high as $17 \%$ of the general population [11], the latter perhaps unsurprising given the increasingly recognized great prevalence of a wide range of allergic and inflammatory disorders which may be rooted at least partly in MCAS), and (2) experience to date (e.g. [12]) suggesting that most MCAS patients, regardless of the (typically decades long) duration of their complex multisystem unwellness prior to diagnosis, eventually identify some regimen which helps them gain significant, largely sustainable improvement. Overdiagnosis, however, also could be problematic. Furthermore, the very recent recognition of "hereditary alpha-tryptasemia" [HAT, a prevalent condition featuring (1) redundancy of the TPSAB1 gene expressing alpha-tryptase and (2) many of the same clinical features as MCAS] is another confounder in the challenges facing the diagnostician considering MCAS. Given that the original proposals for both of the principal schools of MCAS diagnostic thought were first published nearly a decade ago and that multiple updates of each have been published since, we feel that review, and a frank discussion of the pros and cons, of the two proposals, as well as how HAT now "fits in" to diagnostic considerations of MCAS, would be helpful. We follow this analysis with our recommendations for steps forward in research and in practice.

Before diving into this analysis, though, a brief overview of what MCAS is - or at least what it is thought by most to be - may be helpful. The different "schools of thought" proposing different diagnostic criteria have different senses of what the entity of MCAS encompasses, and these different senses drive the differences in diagnostic criteria. However, there is much about MCAS which is uncontested. It is helpful to understand these areas first.

Prior to the introduction of the term "mast cell activation disease" (MCAD) [7], "mast cell disease" was the moniker usually used to refer to the full spectrum of diseases of the MC, which consisted principally of assorted forms of the rare disease of mastocytosis and assorted allergic diseases of varying prevalence ranging from rare (e.g. certain urticarias) to common (e.g. environmental and food allergies). That the allergic illnesses very commonly reflect aberrant MC activation (MCA) was a background biological fact largely lost from conscious consideration in everyday practice. Also often lost was the consideration as to what manifestations of MCA other than "allergic-type" phenomena might also be present in allergy patients.
These patients often experience "non-allergic" problems (commonly inflammatory, sometimes even dystrophic) (see Table 1) potentially rooted in chronic aberrant MCA but which are left to be addressed by non-allergists even less likely to recognize those problems as rooted in MCA. Thus, the only "MC disease" recognized by most health professionals until recently was the range of (prevalent) overtly allergic-type phenomena and (rare) mastocytosis.

In the last 10-15 years, though, it has become apparent that most of the clinical problems in patients with any form of "MC disease" - even mastocytosis - are rooted in the aberrant activation of the abnormal MCs (i.e. aberrant MC mediator production/release), thus leading to the designation of the new term of MCAD to describe the full spectrum of MC diseases, constantly reminding all clinicians of the critical issue of aberrant MC activation in these patients. Because it also became apparent that some MCAD patients did not have either mastocytosis or merely the various defined allergic-type phenomena but in fact a wide range of clinical consequences of MCA, the term "mast cell activation syndrome" was coined to refer broadly to this entity [7].

Table 1 lists symptoms/problems which various MCAS patients commonly exhibit consequent (directly or indirectly) to chronic aberrant MC mediator expression. Other elements, too, though, are needed to make a clear diagnosis of MCAS, and disputes have arisen regarding these elements. For one, laboratory evidence of MCA is highly desirable. However, even if one sets aside arguments about which laboratory criteria should be deemed supportive of an MCAS diagnosis, mere acquisition of laboratory evidence is problematic for much of the world's population without access to these tests. As such, consideration needs to be given to methods of diagnosing MCAS in situations where testing is unobtainable, but disputes have led to differences in diagnostic criteria proposals, thus challenging diagnosticians. Other areas of dispute were therapeutic in nature, namely, the validity of, and approach to, (1) treating patients who have not yet acquired laboratory evidence and (2) incorporating treatment results into diagnostic criteria. Given that impact potentially extends to millions of patients (if the higher estimates of prevalence are closer to the truth), we feel these differences warrant detailed analysis and open discussion.

We focus this paper on (1) rare patients with primary (i.e. clonal) MCAS proven by the presently very limited range of laboratory testing routinely available for proving such [KIT-D816X mutational analysis, and flow cytometry seeking co-expression on the surfaces of MCs of CD117 (the extracellular domain of transmembrane tyrosine kinase KIT, the dominant MC regulatory element) together with CD25 (the alpha chain of the interleukin-2 
Table 1: Common symptoms and findings in MCAD.

\begin{tabular}{|c|c|}
\hline System & Potential manifestations of MCAD \\
\hline Constitutional & $\begin{array}{l}\text { Fatigue, subjective or objective hyperthermia and/or hypothermia, sweats, flushing, plethora or pallor, } \\
\text { increased or decreased appetite, weight gain or loss, migratory pruritus, chemical/physical sensitivities (often } \\
\text { "odd"), poor healing }\end{array}$ \\
\hline $\begin{array}{l}\text { Dermatologic/ } \\
\text { integument }\end{array}$ & $\begin{array}{l}\text { Dermatographism, rashes/lesions of many sorts (migratory patchy macular erythema, telangiectasias, } \\
\text { angiomata, xerosis, striae, warts, tags, folliculitis, ulcers, dyshydrotic eczema), angioedema, alopecia, } \\
\text { onychodystrophy (e.g. brittle and/or longitudinally ridged nails) }\end{array}$ \\
\hline Ophthalmologic & Irritated (often "dry") eyes, episodic difficulty focusing, lid tremor/tic (blepharospasm) \\
\hline Otologic/osmic & $\begin{array}{l}\text { Infectious or sterile otitis externa and/or media, hearing loss and/or tinnitus, dysosmia, coryza, post-nasal drip, } \\
\text { congestion, epistaxis }\end{array}$ \\
\hline $\begin{array}{l}\text { Oral/ } \\
\text { oropharyngeal }\end{array}$ & $\begin{array}{l}\text { Pain or irritation (sometimes "burning"), leukoplakia, ulcers, angioedema, dysgeusia, dental and/or periodontal } \\
\text { inflammation/decay despite good personal and professional attention to dental hygiene }\end{array}$ \\
\hline Lymphatic & $\begin{array}{l}\text { Adenopathy (usually sub-pathologic and spontaneously waxing/waning in size, often migratory), adenitis, } \\
\text { splenitis (typically only modest) }\end{array}$ \\
\hline Pulmonary & $\begin{array}{l}\text { Airway inflammation at any or all levels, cough, dyspnea (usually mild, episodic, “just can’t catch a deep breath" } \\
\text { despite normal pulmonary function tests), wheezing (usually quite mild), obstructive sleep apnea regardless of } \\
\text { weight }\end{array}$ \\
\hline Cardiovascular & $\begin{array}{l}\text { Presyncope [co-diagnosis of postural orthostatic tachycardia syndrome (POTS) is common; full syncope } \\
\text { is relatively rare], hypertension, blood pressure lability, palpitations (usually not correlating with } \\
\text { electrocardiographic events), migratory edema, chest pain (usually non-anginal), atherosclerosis, odd heart } \\
\text { failure (e.g. takotsubo), allergic angina (Kounis syndrome), vascular anomalies }\end{array}$ \\
\hline Gastrointestinal & $\begin{array}{l}\text { Dyspepsia, gastroesophageal reflux, nausea, vomiting (sometimes cyclical), diarrhea and/or constipation (often } \\
\text { alternating), gastroparesis, angioedema, dysphagia (usually proximal), bloating/gas (usually post-prandial, } \\
\text { often acute/subacute, sometimes to the appearance of full pregnancy), migratory abdominal pain from luminal } \\
\text { or solid organ inflammation or distention, malabsorption; cholecystectomy is common, though often yielding } \\
\text { normal pathology; ascites is rare }\end{array}$ \\
\hline Genitourinary & $\begin{array}{l}\text { Migratory luminal and solid organ inflammation (“urinary tract infection," often culture-negative, is commonly } \\
\text { misdiagnosed instead of interstitial cystitis), chronic kidney disease, endometriosis, chronic back/flank/ } \\
\text { abdominal pain, infertility, decreased libido, vulvodynia, vaginitis (often misdiagnosed as infectious), painful } \\
\text { and/or irregular dysmenorrhea, menorrhagia; miscarriages are common and occasionally signal an anti- } \\
\text { phospholipid antibody syndrome possibly rooted in MCAS }\end{array}$ \\
\hline $\begin{array}{l}\text { Musculoskeletal/ } \\
\text { connective tissue }\end{array}$ & $\begin{array}{l}\text { Migratory bone/joint/muscle pain (co-diagnosis of fibromyalgia is common), joint laxity/hypermobility } \\
\text { [co-diagnosis of hypermobile Ehlers-Danlos syndrome (hEDS) is common], osteopenia/osteoporosis } \\
\text { (osteosclerosis is seen but is rare), and other tissue growth/development anomalies (i.e. dystrophisms, usually } \\
\text { benign) such as cysts, fibrosis, vascular anomalies such as hemorrhoids, aneurysms, and arteriovenous } \\
\text { malformations, occasionally even liquid or solid malignancies }\end{array}$ \\
\hline Neurologic & $\begin{array}{l}\text { Headache, sensory neuropathies (most commonly episode/migratory paresthesias in the distal extremities), } \\
\text { episodic weakness (though proven motor neuropathy is rare), dysautonomias, seizure disorders, } \\
\text { "pseudoseizures” (likely dysautonomic events), cognitive dysfunction (most commonly memory, concentration, } \\
\text { and/or word-finding difficulties), dyssomnias (insomnia, frequent waking, hypersomnolence, non-restorative } \\
\text { sleep, restless legs; less commonly or rarely: sleep apnea, sleepwalking, sleep talking, sleep paralysis, night } \\
\text { terrors) }\end{array}$ \\
\hline Psychiatric & $\begin{array}{l}\text { Mood disturbances (e.g. depression, anger/irritability, mood lability), anxiety disorders (anxiety, panic, } \\
\text { obsession-compulsion), attention deficit/hyperactivity; frank psychosis is rare }\end{array}$ \\
\hline $\begin{array}{l}\text { Endocrinologic/ } \\
\text { metabolic }\end{array}$ & $\begin{array}{l}\text { Abnormal electrolytes and liver function tests, hypo- or hyperthyroidism (often just sheer (but modest) lability } \\
\text { of thyroid function), dyslipidemia, impaired glucose control (hyperglycemia, hypoglycemia, glycemic lability), } \\
\text { hypo- or hyper-ferritinemia; nutritional deficiencies are often suspected but are relatively rare, more commonly } \\
\text { micronutrient than general protein/calorie), delayed puberty; adrenal dysfunction is often suspected but rarely } \\
\text { proven }\end{array}$ \\
\hline $\begin{array}{l}\text { Hematologic/ } \\
\text { coagulopathic }\end{array}$ & $\begin{array}{l}\text { Polycythemia or anemia [typically just mild, most commonly normocytic but sometimes macrocytic or microcytic; } \\
\text { other causes (e.g. iron deficiency), whether consequent to MCAS or not, must be ruled out and addressed; } \\
\text { note that "normal" erythropoietic parameters (a relative polycythemia?) may seem odd given the extent of } \\
\text { chronic multisystem inflammation], leukocytosis or leukopenia (typically mild), monocytosis or eosinophilia } \\
\text { or basophilia (typically modest, occasionally moderate or even robust), thrombocytosis or thrombocytopenia } \\
\text { (typically mild), arterial and/or venous thromboembolic disease, otherwise inexplicable "easy" bruising/ } \\
\text { bleeding (co-diagnosis of mild type } 1 \text { von Willebrand disease is common, too); there usually is no histologic or } \\
\text { molecular evidence of MC aberrancy in the marrow in MCAS, but sometimes a modest hypocellularity or mild } \\
\text { myeloproliferative or myelodysplastic appearance is seen, insufficient for diagnosis of a myeloproliferative } \\
\text { neoplasm or myelodysplastic syndrome, and genetic and flow cytometric analyses almost always are normal }\end{array}$ \\
\hline
\end{tabular}


Table 1 (continued)

\begin{tabular}{ll}
\hline System & Potential manifestations of MCAD \\
\hline Immunologic & $\begin{array}{l}\text { Hypersensitivity reactions, increased risk for malignancy and autoimmunity, impaired healing, increased } \\
\text { susceptibility to infection, increased or decreased levels of immunoglobulin of any isotype; monoclonal } \\
\text { gammopathy of undetermined significance (MGUS) is occasionally seen }\end{array}$ \\
\hline
\end{tabular}

Few patients display all of these symptoms; most display subsets, and the heterogeneity of full clinical profiles among MCAD patients is extreme. Most symptoms are chronic and low-grade; some are persistent, but many are either episodic or waxing/waning. More comprehensive lists and discussions, including less common symptoms, are available (e.g. [13-14]).

receptor, dominantly expressed by T-cells) and/or CD2 (ordinarily a surface adhesion molecule restricted to $\mathrm{T} /$ NK-lymphocytes)], and (2) far more common patients with "idiopathic" MCAS, which preliminary research [15-17] strongly suggests is almost always driven by one (largely MC-restricted, largely somatic) mutational profile or another among a very large menagerie of such profiles in KIT and other MC regulatory elements. Unfortunately, such somatic mutational profiling in MCs is not presently available in clinical laboratories, relegating such patients to an "idiopathic" diagnosis. We acknowledge a diagnostic category of "secondary MCAS," but its diagnosis and treatment pales in importance compared to "primary" and "idiopathic" MCAS given that in secondary MCAS, it is expected that treatment of the underlying disorder, which presumably is driving normal activation of the patient's exclusively normal MCs, will result in improvement of the MCAS. As such, all mentions of "MCAS" subsequently in this paper should be taken to refer to primary and idiopathic MCAS. Also, the behavior of cutaneous mastocytosis (CM, grossly limited to cutaneous presentation of mastocytosis, though recent research now suggests all cases of CM, at least in adults, can be found to have circulating, thus systemic, clonal mast cells) [18] shares far more of the behaviors of systemic mastocytosis (SM) than of MCAS. Therefore, all subsequent mentions of "SM" should be taken to refer to SM and CM.

\section{Methods}

We first identified the full sets of literature revealed, as of October 27, 2019, by searches for "mast cell activation syndrome" at both pubmed.gov (138 total articles) and scholar. google.com (1410 total articles). We identified publications offering new or modified schemes for diagnosing the full range of MCAS (excluding those addressing only subsets, such as monoclonal MCAS). We found nine such publications [7-9, 19-24], reviewed them, and found each to fall into one of two principal schools of thought as defined by their original papers $[8,9]$. Our analysis proceeded from these groupings, with attempts to assess each "school" for (1) validity of diagnostic criteria, (2) diagnostic accuracy, and (3) practicality. We also searched similarly for "hereditary alpha-tryptasemia" (HAT) and "TPSAB1" (1 article for the former term and 150 for the latter term at pubmed.gov, 44 for the former and 847 for the latter at scholar.google.com) and read the entirety of the principal papers to date $[25,26]$, as well as a few selected other papers from these searches [2730], to garner insights into the relationships between MCAS and the newly recognized, seemingly similar entity of HAT.

\section{Results}

\section{Valent et al. proposal for diagnostic criteria for MCAS}

The Valent et al., or "consensus," proposal [9] (re-termed here as "consensus-1") and its recent update [22] are described in detail in the first entry in Supplementary Table 1. (Readers are encouraged to review Supplementary Table 1 in detail at this point in order to better understand the following discussion regarding the various diagnostic criteria proposals.) The " $20 \%+2$ " formula for interpreting rises in tryptase, newly introduced in this proposal, as the sole acceptable (even "gold standard") laboratory parameter for diagnosing MCAS bears special attention (again, see Supplementary Table 1).

We remain open to the possibility that " $20 \%+2$ " (or any other formula for interpreting tryptase levels or changes in levels) might be applicable to the broad MCAS population, discriminating that population from the even broader population of those without MCAS. However, we cannot see, given the slew of issues about this formula, that " $20 \%+2$ " can be reasonably viewed yet as a valid (let alone sole, or "gold standard") laboratory diagnostic criterion for MCAS (except possibly in the two uncommon anaphylactic settings referenced in Supplementary Table 1). It remains unclear to what extent "consensus-1" is (or 
warrants becoming) a consensus beyond that sensed by the authors on the papers advocating these criteria.

\section{Molderings et al. proposal for diagnostic criteria for MCAS}

The original and updated Molderings et al. proposals [8, 20, 21] are described in the second entry in Supplementary Table 1. We propose that the Molderings et al. 2017 criteria [21] now be known as the "consensus-2" criteria (to distinguish from "consensus-1"). "Consensus-2" is a consensus, too: another set of criteria regarded by the sizable contingent of investigators authoring this paper as valid for diagnosing the extraordinarily complex and variable disease that is MCAS, compared to a somewhat different perspective held by other investigators who first decided to label their perspective on the disease as a "consensus." We further note there has not yet been even a single study comparing the validity of any one proposal for MCAS diagnostic criteria against any other such proposal. Not that sheer popularity is a good tool for establishing scientific truth, but the consensus-2 proposal in this paper is now endorsed by a much larger group of investigators (from almost all medical specialties) than in the prior Molderings et al. proposals - a group which now collectively has seen well more than 10,000 patients who have behaved clinically and therapeutically in a fashion more consistent with chronic aberrant MCA than any other known pathologic process. This consensus-2 proposal simply presents a different, somewhat "larger" perspective, born of at least equally extensive clinical experience as held by the consensus-1 authors, regarding the natural behavior of a large set of diseases which appear to have a common root in chronic aberrant MC activation, with only modestly increased MC accumulation not rising to the gross levels, and with abnormal MC histomorphology, seen in SM.

It is not yet known which proportions of the populations afflicted by any of the many comorbidities often seen with MCAS [e.g. myalgic encephalitis/chronic fatigue syndrome (ME/CFS), fibromyalgia, irritable bowel syndrome (IBS), postural orthostatic tachycardia syndrome (POTS), small fiber neuropathy (SFN), hypermobile Ehlers Danlos Syndrome (hEDS), and many others] [12] actually have MCAS, and whether each of those comorbidities is truly caused by MCAS or is merely associated with MCAS. Generally, those favoring the consensus-2 criteria have observed non-trivial overlaps among the populations with these diseases (e.g. [31-35]), hinting at commonalities in these diseases' mechanistic roots, and those favoring the consensus-1 criteria have published contrary assertions (e.g. $[23,24,36])$.

\section{Other proposals for diagnostic criteria for MCAS}

Three additional proposals $[19,23,24]$ - all modest variants of the "consensus-1" criteria - have emerged, as detailed in the third through fifth entries in Supplementary Table 1.

\section{Discussion}

MCA disorders (largely as allergic-type diseases and more complex presentations now termed "MCAS") are prevalent, judging merely by the known $10-50 \%$ global prevalence of allergy (e.g. [37-43]). This figure unsurprisingly is congruent with not only some of the higher estimates of prevalence for MCAS [11, 44, 45] but also (given that chronic multisystem inflammation is, more than any other clinical feature, the sine qua non of MCAS) estimates for prevalence of the spectrum of chronic inflammatory diseases [43, 46, 47]. Mastocytosis, on the other hand, is a rare disease [20]. As such, the global impact of accuracy in diagnosing MCAS likely is much greater than in diagnosing SM.

For any disease, misdiagnosis (whether underdiagnosis or overdiagnosis) is problematic for patients and society, typically delaying (or even permanently preventing) patients from accessing effective treatment and, thus, perpetuating suffering and even disability and the accompanying loss of productivity. Many studies (e.g. [48-52]) have shown misdiagnosis is common, even for common disorders. MCAD, too, is challenging to learn to recognize and challenging to diagnose [12, 34, 53]. Given the extraordinary array of MC mediators and their extraordinary arrays of direct and indirect, local and remote, acute and delayed and chronic effects in cells/tissues/organs/ systems throughout the body, it seems likely that MCAD would be an area especially prone to misdiagnosis, largely in the form of patients misdiagnosed with diseases in truth consequential to MCAD as opposed to other diseases (e.g. carcinoid) being misdiagnosed as MCAD. This latter risk likely can be substantially tempered by the diagnostician's diligence in adherence to the criteria, including absence of processes/diseases other than chronic aberrant MCA, which better account for the full range and duration of the patient's problems. Differential diagnoses for MCAS have been considered in the literature (e.g. [20,34]); a few such considerations include diabetes mellitus, porphyria, 
sarcoidosis, thyroid disorders, Fabry disease, Helicobacter pylori gastritis, infectious and inflammatory bowel and skin and genitourinary tract diseases, celiac disease, lactose/sucrose/fructose intolerance, amyloidosis, intestinal adhesions/volvulus/obstruction, hepatitis, cholecystitis, median arcuate ligament syndrome, neuroendocrine cancers (carcinoid, pheochromocytoma, etc.), pancreatic endocrine tumors, food/environmental allergy, asthma, allergic rhinitis, eosinophilic esophagitis/enteritis, other hypereosinophilic and hyper-IgE syndromes, immunodeficiencies, autoinflammatory syndromes, hereditary angioedema, vasculitis, hypermobility syndromes, lymphoma, myeloproliferative neoplasms, autism, anxiety/ panic, depression, psychosomatism, conversion disorder, and Munchausen's syndrome. As merely one example of the intersection of MC activation with other diseases, MCs closely interact with neurons $[54,55]$ and can be activated and increased in numbers in gastrointestinal neuropathic disease [56]. Full thickness luminal gastrointestinal tract biopsy may be important in the diagnosis in carefully selected cases where gastrointestinal tract dysmotility is evident and MC disease is suspected [57], but the utility of this approach in patients with luminal gastrointestinal tract dysmotility overall remains unclear and needs more research, especially given our own experience that more commonly obtained, safer (especially given the association of MCAS with diseases of connective tissue frailty), non-full-thickness (i.e. mucosal and submucosal) biopsies usually are sufficient for assisting in diagnosis of MCAS (with or without gastrointestinal dysmotility) by the consensus- 2 criteria. All in all, careful consideration by the diagnostician of the full spectrum of the patient's problems is needed, as well as recognition that some accurate diagnoses (e.g. chronic idiopathic urticaria), though perhaps subsumed by a more encompassing diagnosis of MCAS, may, nevertheless, be effectively addressed by standard treatment for the more limited diagnosis.

The extent of unnecessary suffering from underdiagnosis of MCAS is amplified by present estimates of prognosis in MCAS of a normal lifespan in most. Delay in access to effective treatment for MCAS may stretch decades and likely was present lifelong before MCAS became recognized. (Indeed, an MCAS patient's history often will date back to a childhood of excessive "colic," "allergies," "food intolerances," dysmenorrhea/menorrhagia soon after menarche, and other inflammatory or allergic-type problems either incorrectly diagnosed as normal or dismissed as of unknown cause and insignificant.) The adverse consequences on both personal and societal scales seem incalculable. In our collective experience, most patients diagnosed with MCAS using the consensus-2 criteria experience meaningful improvement - sometimes quite astounding improvement - with MC-directed therapies no matter the years to decades they have suffered with previously unexplained multisystem issues not infrequently leading to partial or full disability.

Despite important agreements among the diagnostic proposals (see Table 2), comparison reveals significant differences. The "consensus-1" proposal - based on clinical observations of a highly experienced but relatively small group of investigators focused principally in SM (a disease significantly different from MCAS in key serologic, histomorphologic, and genetic factors) - considers only severe, recurrent flares of a small number of specific symptoms as meaningful in determining a diagnosis of MCAS; the modified AAAAI proposal even requires recurrent anaphylaxis. The "consensus-2" proposal - also based on clinical observations of a highly experienced, large group of clinicians and investigators increasingly focused on MCAS - considers a far wider range of symptoms (all consistent with known effects of the established great repertoire of MC mediators) which often respond to MC-targeted therapies, thus making it seem reasonable to consider, in appropriate clinical context (i.e. not with any one symptom observed in isolation), diagnostic utility in this larger range of symptoms. Carefully designed and executed research will be required to identify whether either proposal is considering the most correct range of symptoms or should regard as diagnostically useful a smaller - or a greater - range of symptoms.

Table 2: Broadly accepted characteristics defining the mast cell activation syndrome (MCAS) population.

1. An MCAS patient must have symptoms consistent with chronic MCA, which is aberrant (i.e. abnormal, whether constitutive/baseline and/ or reactive to some identifiable trigger; note most MCAS patients have both constitutive and reactive MCA, even if either form is just to a modest degree at a given point), and, in many patients, accompanied by periodic flares (a.k.a. "spells," "episodes," and such) of certain subsets of their symptoms

2. An MCAS patient must have signs/symptoms of aberrant MCA in multiple (i.e. at least two) organ systems

3. An MCAS patient must (with reasonable confidence) not have some other disease accounting better than MCA for the full range and duration of the observed symptoms/signs

The characteristics listed here are a synthesis of the published proposals for diagnostic criteria for MCAS [7-9, 20-22, 24]. 
The proposals differ, too, in the laboratory criteria they consider. The consensus-1 proposal asserts (though seemingly without evidence) that a rise in serum total tryptase by " $20 \%+2$ " $\mathrm{ng} / \mathrm{mL}$ is a preferred marker of MCA, though if a patient cannot be shown to have " $20 \%+2$," then elevations in a few other relatively MC-specific mediators can be considered diagnostic. These other mediators include prostaglandin $\mathrm{D}_{2}\left(\mathrm{PGD}_{2}\right)$ or its immediate $11-\beta-\mathrm{PGF}_{2 \alpha}$ metabolite, and urinary histamine metabolites [generally taken to be just $N$-methylhistamine ( $N$-MH) as $N$-methylimidazolacetic acid (MIMA) is no longer readily testable at clinical laboratories, at least in the United States]. The "consensus-2" proposal states that levels of a slightly wider range of mediators relatively specific to the MC [tryptase, chromogranin A (CgA), heparin, $\mathrm{PGD}_{2}$, histamine, $\mathrm{N}-\mathrm{MH}$, $11-\beta-\mathrm{PGF}_{2 \alpha}$, and leukotriene $\mathrm{E} 4$ (LTE4)], which rise above their normal ranges can be taken as diagnostic laboratory evidence of MCAS in the proper clinical context of otherwise unexplained chronic multisystem issues of generally inflammatory \pm allergic \pm dystrophic themes. Like tryptase, heparin is highly (though not perfectly) specific to the MC [58], and some published research now suggests an elevated plasma heparin level likely is the single most sensitive marker of MCA, with approximately $80 \%$ of patients clinically demonstrating symptoms consistent with MCA showing increased levels of plasma heparin when measured using a sufficiently sensitive assay [58]. In clinical practice, the biological and logistical challenges of measuring heparin need to be addressed to ensure accurate results. CgA is a known product of the $\mathrm{MC}[59,60]$, and if the few other diseases known to produce elevated chromogranin A (heart or kidney or liver failure, proton pump inhibitor use, neuroendocrine cancer, chronic atrophic gastritis) can be reasonably confidently excluded in a patient with symptoms consistent with chronic aberrant MC mediator release, it seems reasonable to consider that an elevated serum CgA level likely is stemming directly from the aberrantly activated MCs. $\mathrm{PGD}_{2}$ is produced by several types of cells [61-69], but the MC produces roughly a thousandfold more $\mathrm{PGD}_{2}$ than any of the other types of cells [70,71], so when an elevated $\mathrm{PGD}_{2}$ level - in serum and/or urine - is seen in a patient with symptoms consistent with MCA, it seems most likely that the elevated $\mathrm{PGD}_{2}$ level is dominantly sourced from dysfunctional MCs. $11-\beta-\mathrm{PGF}_{2 \alpha}$ is the principal immediate metabolic product of both $\mathrm{PGD}_{2}$ and $\mathrm{PGE}_{2}$ [72-74]. Although the MC is known to bear receptors for $\mathrm{PGE}_{2}$ [75-77], it appears to produce only low levels of $\mathrm{PGE}_{2}[78]$ and does not appear to increase $\mathrm{PGE}_{2}$ production in inflammatory conditions [79], so it is possible that elevated levels of $11-\beta-\mathrm{PGF}_{2 \alpha}$ may be rooted in activation of cells other than MCs, which are producing elevated levels of $\mathrm{PGE}_{2}$ (e.g. endothelial cells [79]). Yet, when an elevated level of $11-\beta-\mathrm{PGF}_{2 \alpha}$ is seen in the context of symptoms more consistent with MCA than other processes, it seems reasonable to consider that the elevated $11-\beta-\mathrm{PGF}_{2 \alpha}$ level is sourced primarily from dysfunctional MCs. More recently, it has been suggested that $17-\beta-\mathrm{PGD}_{2 \alpha}$ is the best of the $\mathrm{PGD}_{2}$ metabolites to measure in seeking evidence of MCA, but this test is not yet routinely available at any commercial clinical laboratories [80]. Histamine is produced by the MC and a range of other cells [81], and it is acknowledged that histamine, like tryptase and $\operatorname{CgA}$, can be elevated in a range of diseases and pathologic states. Yet, again, when histamine is found elevated (in whole blood, serum, plasma, or urine) in the context of symptoms more consistent with chronic aberrant MC mediator release than any other known pathologic process, it seems reasonable to consider that the elevated histamine level is sourced primarily from dysfunctional MCs. Via histidine N-methyltransferase, $\mathrm{N}$-MH is the principal immediate metabolic breakdown product of histamine filtered by the kidney into the urine $[82,83]$, but given the range of possible cellular (and even dietary) sources of histamine, it would seem no more feasible to pinpoint the source of an elevated $\mathrm{N}-\mathrm{MH}$ on MCA than on any other process producing an elevated level of histamine. Thus, we again note the importance of context in interpreting relevant findings in an MCAS patient and assembling an overall clinical picture more supportive of this diagnosis and less supportive of any other.

With the possible exceptions of heparin and tryptase, it simply is not possible at present to identify the precise range of cellular sources for each of the mediators presently proposed for testing in one MCAS diagnostic proposal or another. Therefore, it would seem to be unnecessarily restrictive to exclude consideration of, say, histamine testing or CgA testing simply because one can never be perfectly sure that such mediators are dominantly MC sourced.

Identification of other mast cell mediators which might have utility in diagnosing MCAS is an area of active investigation (e.g. [84, 85]), but questions remain regarding whether such mediators (e.g. interleukin-1 $\beta$ [84] and interleukin-6, interleukin-31, tumor necrosis factor, or vascular endothelial growth factor [85]) are "sufficiently" specific to the MC to warrant their having significance visà-vis a diagnosis as important as MCAS. It is possible that some MC mediators, while being of insufficient specificity for diagnostic purposes, may nevertheless eventually demonstrate utility for therapeutic efficacy monitoring purposes in at least some MCAS patients, i.e. in at least some variants of MCAS.

As it is presently worded (in both the original proposal in 2012 and the "update" in 2019), the "consensus-1" 
proposal requires that MCAS patients demonstrate at least partial response to antihistamines and/or cromolyn as an essential diagnostic criterion, while the "consensus-2" proposal permits demonstration of such a response to be considered a minor diagnostic criterion. It is understood that both diagnosis and therapy are imprecise arts, and it often is the case in practice that therapeutic response (or lack thereof) leads to alterations in diagnostic thinking. However, we are unaware of other diseases for which diagnostic criteria require demonstration of therapeutic response. Generally, it is acknowledged that diagnosis is what should principally inform therapeutic decision making. It is concerning, too, that treatment response be required to establish diagnosis of a disease of complexity so great it seems virtually certain that at least some patients might not respond to any of the therapies presently known to have utility in some patients. Accurate diagnosis would still be important in such patients visà-vis forthcoming treatments. It also is concerning that specification of such a limited set of treatment options in a proposal for diagnostic criteria might suggest to most practitioners that if the patient does not respond to any of these few treatments, then it must not be possible for the patient to have the disease - a precept which is highly unlikely given, again, the extraordinary complexity and heterogeneity of the disease (implying, and as has actually been found, a large array of treatments found helpful in various patients). Thus, in an effort to avoid underdiagnosis - especially of a disease which, once diagnosed, usually is effectively treatable in one fashion or another - listing of specific treatments in a set of diagnostic criteria would seem to be counterproductive. In our experience, the range of treatments effective in patients meeting "consensus-2" criteria is far broader than those listed in the "consensus-1" criteria.

Although none of the published proposals for diagnostic criteria for MCAS comprehensively specifies the types or numbers of mast cell stabilizers or mediator antagonists, doses, or durations which should be tried to establish the therapeutic response considered by some proposals as a required or optional diagnostic criterion, treatments commonly tried early, at standard doses as used in most other applications, include $\mathrm{H}_{1}$ and $\mathrm{H}_{2}$ histamine receptor antagonists, leukotriene receptor antagonists, cromolyn, and, in patients without prior adverse reactions to such, non-steroidal anti-inflammatory drugs. Treatment response criteria (e.g. "partial response," "complete response") have not yet been defined by any group, and this is likely to be a challenging endeavor in itself given that the complex (patho)physiology of the disease sometimes results in finding unexpected benefits rather than expected benefits. Clinical judgment, taking into account observed symptoms and findings and known mast cell (patho)physiology, is appropriate in treating MCAS, often starting inexpensively. Setting aside the observation that rapid demonstration of intolerance of a drug being tried for MCAS should immediately invite cessation of the drug and consideration of potential excipient-driven reactivities, in our estimation most drugs tried for MCAS which do not demonstrate clear benefit by 2-4 weeks after having reached a "reasonably potent" dose should be abandoned out of futility. A comprehensive review of the pharmacotherapy of MCAS has been published [86].

The theme we are constantly reminded in our considerations of various proposals for diagnostic criteria for MCAS is that MCAS is a very complex disease from the clinical to the molecular level (including mediators, genes, and epigenes) [11, 15-17, 80]. As such, a clinical diagnosis of MCAS - i.e. a case of MCAS worthy of treatment - virtually certainly will never rest on meeting merely a single diagnostic criterion (e.g. a single laboratory test meeting a specific threshold). As is the case with most syndromes, the diagnosis of MCAS will continue for many years to come to rest on the demonstration of a specific constellation of findings, i.e. the presence of each finding in the context of other findings also congruent with the diagnosis. In such a scheme, where the presence of multiple criteria creates a natural system of "checks and balances," the likelihood of misdiagnosis based on inappropriate interpretation of any one observation in the patient dramatically diminishes.

\section{How does familial hypertryptasemia fit into the mast cell disease construct?}

First described merely a few years ago by investigators in Spain [25] and at the U.S. National Institutes of Health [26], familial hypertryptasemia, also termed hereditary alpha-tryptasemia (HAT), has been defined as a chronically elevated serum tryptase level coincident with the finding of redundant copies of the alpha tryptase gene TPSAB1 (though even that definition has been challenged by the finding that $\sim 8 \%$ of the patients with redundant TPSAB1 have no elevations in tryptase). HAT appears to be prevalent (approximately $4-6 \%$ of the population), and the described clinical spectrum of HAT seems to fit well within that of MCAS. Thus far, no differences have been identified between prognosis or recommended management for HAT patients vs. MCAS patients, and the finding of HAT patients with normal tryptase levels raises other questions. To what extent (if any) are the elevations in 
tryptase seen in most HAT patients, and the redundant TPSAB1 genes seen in all HAT patients (by definition), actually causing the chronic aberrant MC release of a wide range of mediators suggested by the wide range of symptoms in these patients (as in most MCAS patients)? Or, is TPSAB1 redundancy merely associated with other mutations more responsible for driving the aberrant constitutive and reactive MC mediator release in HAT patients? Furthermore, although the principal function of tryptase is not yet known $[87,88]$, the range of what is known about tryptase's biological functions makes it unlikely that the modest elevation in tryptase seen in most HAT patients would be the driver of any of their symptoms, let alone most or all of their symptoms. As such, it seems likely that the redundant TPSAB1 genes and the modestly elevated tryptase levels in HAT patients are associated with, but not causative of, the MCAS-like symptoms catalogued in most HAT patients. At present, then, HAT appears to us to be merely one of the myriad of subsets of MCAS (such as some of the rare inborn autoinflammatory syndromes are increasingly appearing to also be). Therefore, given that there are no prognostic or therapeutic differences yet identified between HAT and MCAS, it would appear that the only utility in TPSAB1 testing is in investigative settings and in pursuing a diagnosis of MCAS per consensus-2 criteria in patients with a persistent, mild tryptase elevation (e.g. $\leq 20 \mathrm{ng} / \mathrm{mL}$ ), as such a finding (inferring the elevated tryptase level might be stemming from the TPSAB1 redundancy and that such a redundancy might actually be merely an incidental finding with no clinical effects) might then incline the diagnostician to search for additional (non-tryptase-based) laboratory evidence of MCA before making a definitive diagnosis.

\section{Why the rush?}

This question is imperative in judging at this time the validity/utility of the various proposals for MCAS diagnostic criteria. At this very early point in our understanding of an obviously extremely complex disease (as one would expect of a disease rooted in a cell intrinsic to the survival of all eukaryotes for $>500$ million years now) [89], it is unclear why only one proposal for diagnostic criteria should be considered acceptable. There likely will be many revelations to come in the basic and clinical sciences of MCA, which will significantly affect valid MCAS diagnostic criteria. Despite the problems readily apparent with the consensus-1 proposal for diagnosing MCAS, it need not be dismissed or replaced at this time. Instead, there presently seems to be ample room for using both the consensus-1 and consensus-2 proposals (and likely others, too) for diagnosing MCAS (analogous to how evolving, steadily more complicated proposals for diagnostic schema for mastocytosis, sometimes with "provisional" declarations, frequently emerge), especially as it seems increasingly likely that the consensus-1 criteria simply diagnose a severe but fortunately small subset of the patients diagnosed by the consensus- 2 criteria. We thus propose that either the consensus- 1 or consensus- 2 proposal be accepted for diagnosing any given case of MCAS until criteria can be developed using the modern, robust methodologies now being employed to create classification criteria for similarly complex and heterogeneous conditions such as lupus [90]. It has been little more than a decade since the first case reports of MCAS were published; there have not yet been any large-scale studies of any aspects of the disease, though a few small-scale such studies are beginning to emerge [12, 33, 91]. As such, we fail to see why there must be a rush to pronounce only one approach as definitively diagnostic of a disease of such complexity/heterogeneity. We acknowledge there would be advantages to a single approach (principally, comparability of patient populations for research purposes, thought it should be noted that mutational studies to date (e.g. [15-17]) have shown great mutational heterogeneity in all MCAS patient populations so studied thus far, thus questioning the very feasibility of studying homogeneous MCAS populations). On the other hand, it seems likely there would be significant drawbacks (principally, underdiagnosis from inappropriately narrow criteria) to making premature judgments about diagnostic criteria for such a yet poorly understood complex/heterogeneous entity. If alternative ways come to be recognized to diagnose a disease whose clinical behavior seems more easily attributable to chronic MCA than any other recognizable process - and especially when such diagnoses clearly lead to effective treatments benefiting previously unimprovable patients - then why not at least tentatively accept multiple diagnostic approaches with open arms and allow the time needed to adequately vet the true validity of any given diagnostic proposal? The perpetuated suffering, and occasionally even mortality, consequent to underdiagnosis seems counter to the fundamental goal and guiding principle of all forms of medicine.

\section{Drawbacks in practice and in research to two different diagnostic proposals}

As implied above, the principal drawback in clinical practice, and, even more importantly, in research, to the 
persistence of two proposals for diagnostic criteria for MCAS is obvious: the inability to compare populations diagnosed by one set of criteria against populations diagnosed by the other set of criteria.

It is obvious that incomparability is a substantial drawback. In clinical practice, diagnostic assessment tools which fit well with one proposal may not fit well with other proposals; treatment approaches (individual drugs, algorithms, etc.) which work well for MCAS diagnosed by one proposal may not work as well for MCAS diagnosed by any of the other proposals. In research, incomparability obviously limits a study's applicability to the population in general and thus diminishes the overall value of a study, certainly not an insignificant consideration in these days of substantial clinical trial costs.

Another drawback is clear, too: practitioners may find an already complex field rapidly becomes unmanageably complex in trying to understand which diagnostic and therapeutic approaches will best apply to the individual patient. Some practitioners may use unmanageable complexity as a reason not to consider the diagnosis at all.

Of course, to expect simplicity in diagnostic criteria in such a complex disease would seem to be folly, and though it is less pleasant to deal with complexity than to deal with simplicity, MCAS is the complex beast that it is. Though it is always desirable to try to reduce complexity, at some point complexity cannot be reduced further without incurring unacceptable adverse consequences.

Fortunately, these drawbacks, in fact, do not preclude pursuing clinical research in MCAS; they merely complicate the matter, an outcome which seems unavoidable and perhaps should be embraced (as an opportunity to better understand the many variants of the disease) rather than feared or avoided. Friendly competition among proposals for diagnostic criteria even sets a stage upon which clinical trials can rigorously compare proposal performance - certainly a worthy objective expected to help the field progress toward harmonization of proposals, and, in the end, improved clarity for patients and practitioners alike.

\section{Suggested steps forward in practice}

MCAS likely is prevalent [11]. As such, ignorance or diminishment of it disserves individual patients as well as society at large, raising costs to the health care system and diminishing worker productivity. The disease is complicated and will become ever more so as its pathophysiology is increasingly unraveled and as its likely great many distinct variants come to be identified. Therefore, it seems the greatest human good would come first from diagnosis - by any set of peer-reviewed, published criteria

Table 3: Suggested steps forward in MCAS practice in 2020.

1. We advocate diagnosing MCAS in routine clinical practice based on either of the two peer-reviewed, published proposals for diagnostic criteria for MCAS [i.e. the latest iteration of consensus-1 [22] (or its more neuro-inclusive predecessor [9]) or the latest iteration of consensus-2 [21]], thereby giving the patient access to concerted therapeutic efforts which are likely to gain significant improvement the patient (and society) will enjoy for decades to come. In other words, although the preference for science-grounded practice by all health care professionals is recognized, nevertheless, when prioritization becomes necessary, our authorship - a broad collaboration of academicians and community practitioners, generalists and specialists of all sorts, including physicians and a broad array of other health care professionals, representing truly global thought in this area across five countries on three continents in both hemispheres - strongly recommends that practitioners serve human needs first and science second.

2. Therapies supported by peer-reviewed published evidence obviously are to be preferred over those without such, and higher grades of evidence obviously are to be preferred over lower grades. Also, it almost always is better to pursue truly novel therapies in the context of an appropriately designed, approved, and monitored clinical trial. However, again, it is merely a decade since the first case reports of MCAS were published, and thus a paucity of published evidence supporting various therapies, and many defects in trial design and execution, must be expected for decades to come. These deficiencies should not hinder efforts at applying treatments with reasonable risk:benefit ratios as (1) most of the present treatments for MCAS bear little risk at the doses typically effective in MCAS, and (2) again, most MCAS patients do manage to eventually identify significantly helpful treatment even in spite of having suffered progressive sickness and debility from their illness for decades. There are many reasons to expect it will take a long time before our profession learns how to design and conduct MCAS studies well and to make truly reliable conclusions from such research. We may know very little thus far about MCAS, but even just the little we do know is turning out to be enough to significantly help most MCAS patients. Thus, it would be a shame for our profession if many such patients were to continue suffering for decades, years, or even a month longer than necessary just because a perfect, unified set of diagnostic criteria or clearly reliable therapeutic guidance is not yet available.

3. As awareness of MCAS within the general medical community widens, the pace of research, including the opening of clinical trials, will accelerate. As can be said for any disease, advancement of the science usually comes best from rigorous research, so clinicians are strongly encouraged to remain abreast of research developments and opportunities (e.g. periodically searching clinicaltrials.gov for "mast cell" or "mast cell activation syndrome," or subscribing to research notification services) and to enroll their MCAS patients in clinical trials (whether diagnostic, therapeutic, or even merely studying the natural history) to the extent feasible. 
- and then from attempted treatment with any therapy which has been found helpful in at least some population of MCAS patients. Such generalities, of course, neither excuse MCAS-treating clinicians from being judicious in use of diagnostic criteria and in selection of therapies to be tried (especially given the extreme costs of some therapies) nor excuse MCAS investigators from pursuing welldesigned and -executed studies to make clear the manners in which assorted specific variants of the disease behave, both in their natural courses and in response to various treatments. Further practice recommendations are noted in Table 3.

\section{Suggested steps forward in research}

As previously noted, the complexity of MC biology (especially the large number of mediators produced by the MC and each mediator's typically large menagerie of effects), together with the data to date suggesting a menagerie of mutations (mostly somatic) is present in the dysfunctional MCs in most primary MCAS patients [15-17], inescapably creates a very large pool/collection of variants of MCAS. Each variant has its own complex pathophysiology, with similarities among some cases of MCAS but also many differences which seem likely to be among the principal

Table 4: Suggested steps forward in MCAS research in 2020.

1. Given the challenges created by the complexity and heterogeneity of MCAS, and though recent trends in the conduct of clinical trials have emphasized diversity in the recruiting of subjects, MCAS would seem to be an investigational arena calling for even greater precision in eligibility criteria, and restriction in diversity, than have historically been defined. In fact, given the likely significant prevalence of MCAS in the general population, together with the extreme heterogeneity of the disease's behavior at all levels, even the eligibility criteria for "healthy control subjects" probably could stand some "tightening" to ensure (to a reasonable, affordable extent) that such subjects likely do not harbor MCAS. For example, in a study investigating mast cell densities in luminal gastrointestinal tract biopsies, it would be insufficient to use "routine screening colonoscopy" patients as "healthy control subjects" unless careful histories have been taken from, and physical examinations conducted on, such subjects by an MCAS-familiar clinician to provide reasonable assurance they likely do not have MCAS. Otherwise, the "healthy control" cohort could become sufficiently "contaminated" by subjects with unrecognized MCAS as to impair the study's ability to detect distinctions between healthy people and MCAS patients. Examples abound with significant adverse consequences in practice arising from poor clinical trial design leading to false conclusions of differences between "control" and "affected" cohorts. The complexity of MCAS would seem to only heighten the risk for such consequences unless similarly heightened care is taken with regard to trial design.

2. Unless it is specifically the heterogeneity of MCAS one is seeking to characterize in a study (e.g. [12]), studies examining "general" populations of MCAS patients probably are inadvisable, at least until diagnostic evaluation for MCAS advances to where identification of the MC mutational profiles likely driving most cases of the disease are routine and provide some expectation of harmony in clinical behavior among the patients recruited for a given study.

3. It seems more appropriate to design MCAS-related studies focused specifically in cohorts with certain associated co-morbidities suspected to be underpinned by one particular variant (or a relatively small collection of variants) of MCAS. Perhaps a good starting point would be to develop a small "industry" of pilot studies examining the prevalence of laboratory-proven MCAS (as diagnosed by one diagnostic criteria proposal or another, per the preference of an individual study's investigators) within cohorts of patients with one co-morbidity or another [e.g. myalgic encephalitis/chronic fatigue syndrome (ME/CFS), fibromyalgia, irritable bowel syndrome (IBS), postural orthostatic tachycardia syndrome (POTS, hyperadrenergic (haPOTS) and otherwise), hypermobile Ehlers-Danlos syndrome (hEDS), etc.]. At a minimum, this approach would permit the prevalence of laboratory-proven MCAS (whether primary, secondary, or idiopathic) within the cohort with that co-morbidity to be defined, perhaps showing, for at least some of those co-morbidities, a nontrivial prevalence of MCAS and thus a possible new etiologic consideration for at least certain fractions of the populations with these various co-morbidities which have long defied great extents of etiologic investigations.

4. Whenever possible, such initial comorbidity-specific MCAS-prevalence studies should be accompanied simultaneously by correlative science studies in which, similar to prior studies [15-17], MC mutational profiles (and epigenetic profiling, too, if feasible) are sought in the studied subjects. Given that the subjects studied in the prior studies were "general MCAS patients," with great heterogeneity in their clinical presentations, it is not surprising that such great heterogeneity was also found in the studied subjects' MC mutational profiles. However, it is possible, perhaps even likely, that studies of the MC mutational profiles in cohorts of MCAS patients sharing similar clinical presentations (e.g. a cohort of patients with only hEDS, or at least with hEDS and a very limited range of additional comorbidities) might discover recurrent mutational profiles (in genomes and even epigenomes) which might be essential in finally unraveling the full pathobiology of hEDS and the many other comorbidities found among the "general MCAS population."

5. The design of studies investigating molecular mechanisms for the various clinical (mis)behaviors seen in some MCAS patients should take into consideration that not all of the dysfunctional MCs in an MCAS patient are dysfunctional in the same manner or at the same time. As such, study design probing local, brief expression of (often quite thermolabile) MC mediators may be more revealing than study design probing systemic, sustained mediator expression. Such studies may well first require development of new technologies, including molecular radiographic technologies such as whole-body imaging of expression of a potent vasodilator such as PGD during a flare of presyncopal symptoms in a patient with laboratory-proven haPOTS and MCAS. 
challenges of MCAS to the diagnostician. It can be challenging to recognize that MCAS should be considered in differential diagnosis of a patient's presenting assortment of symptoms and findings when the clinical presentation can substantially differ from one patient to the next. The disease even can vary substantially in its behavior within a given patient from one point in time to another (e.g. alternating diarrhea and constipation are common), and even from one site to another in the same patient at the same point in time (e.g. osteopenia/osteoporosis at some bony sites and, simultaneously, osteosclerosis at other sites). These multiple dimensions of heterogeneity create tremendous problems for rigorous study of the disease. Each patient in a study of "general" MCAS patients may well be more of an " $\mathrm{N}$ of 1 " than seen with each patient in studies of most other diseases, making it very difficult to reach definitive conclusions and quite possibly missing important diagnostic and therapeutic signals present only in various subsets of the MCAS population. We summarize our recommendations for addressing these challenges in Table 4. Clearly, the complexity and heterogeneity of MCAS and the challenges to research posed by various essential elements of MCAS biology/pathobiology such as the brief half-lives and thermolability of many of the MC's mediators constitute further reason to expect the road ahead in this arena will be difficult and slow and further reason for measured consideration of diagnostic and therapeutic recommendations rather than rushes to judgment.

\section{Conclusions}

Mast cell activation syndrome (MCAS) is a recently recognized clinical entity increasingly appreciated to be the correct root diagnosis (i.e. implying response to corresponding therapy) for a large number of patients previously found to have a large assortment of seemingly idiopathic chronic multisystem issues of general themes of inflammation \pm allergic-type issues \pm dystrophisms. MCAS is extraordinarily complex and heterogeneous in its clinical behavior, and as so much remains to be discovered about the underlying biology and pathobiology of the MC, it seems likely that appreciation of the full range of clinical (let alone molecular) behavior of the disease will continue expanding for decades to come. Given such expectations, it seems wise to remain receptive to at least some variation in views of the disease's behavior and of appropriate diagnostic and therapeutic management, and to welcome new views which, taking advantage of new research, may explain more observations than perhaps afforded by older views. Risk of overdiagnosis likely can be managed relatively well by adhering to peer-reviewed, published criteria. All in all, there is space for many years to come to accommodate not only both the consensus-1 and consensus-2 proposals for diagnosing MCAS but also other proposals which may emerge. It seems likely that far more research will be needed before it may become appropriate to make a concerted effort to harmonize discordant proposals. We recognize the WHO for its insight in this matter as manifested by its not considering MCAS in its recent revision [92] of its consensus diagnostic criteria for mastocytosis, and we caution against premature conclusions at other upcoming meetings given the marked individual and societal risks from underdiagnosis of what likely is a very prevalent disease.

Author contributions: Dr. Afrin was the principal author; Dr. Molderings was the senior investigator. All other authors contributed equally to the writing of the paper and are listed in alphabetical order. All the authors have accepted responsibility for the entire content of this submitted manuscript and approved submission.

Research funding: Author LAP, U.S. National Institutes of Health, Office of Research on Women's Health, Grant No. K12HD085852.

Employment or leadership: None declared.

Honorarium: None declared.

Competing interests: The funding organization(s) played no role in the study design; in the collection, analysis, and interpretation of data; in the writing of the report; or in the decision to submit the report for publication.

Disclaimer statement: All authors report they have no conflicts of interest and had full access to all of the text in this submission and take responsibility for the integrity of any factual statements and analysis. This work has not been presented previously in any other form or venue.

\section{References}

1. Roberts 2nd LJ. Recurrent syncope due to systemic mastocytosis. Hypertension 1984;6(2 Pt 1):285-94.

2. Roberts 2 nd LJ. Carcinoid syndrome and disorders of systemic mast-cell activation including systemic mastocytosis. Endocrinol Metab Clin North Am 1988;17:415-36.

3. Roberts 2 nd LJ, Oates JA. Biochemical diagnosis of systemic mast cell disorders. J Invest Dermatol 1991;96(3 Suppl):19S-24; discussion 24S-25S; 60S-65S.

4. Sonneck K, Florian S, Müllauer L, Wimazal F, Födinger M, Sperr WR, et al. Diagnostic and subdiagnostic accumulation of mast cells in the bone marrow of patients with anaphylaxis: monoclonal mast cell activation syndrome. Int Arch Allergy Immunol 2007;142:158-64. 
5. Akin C, Scott LM, Kocabas CN, Kushnir-Sukhov N, Brittain E, Noel $\mathrm{P}$, et al. Demonstration of an aberrant mast-cell population with clonal markers in a subset of patients with "idiopathic" anaphylaxis. Blood 2007;110:2331-3.

6. Valent P, Akin C, Escribano L, Födinger M, Hartmann K, Brockow $\mathrm{K}$, et al. Standards and standardization in mastocytosis: consensus statements on diagnostics, treatment recommendations and response criteria. Eur J Clin Invest 2007;37:435-53.

7. Akin C, Valent P, Metcalfe DD. Mast cell activation syndrome: proposed diagnostic criteria. J Allergy Clin Immunol 2010;126:1099-4e4.

8. Molderings GJ, Brettner S, Homann J, Afrin LB. Mast cell activation disease: a concise practical guide for diagnostic workup and therapeutic options. J Hematol Oncol 2011;4:10.

9. Valent P, Akin C, Arock M, Brockow K, Butterfield JH, Carter MC, et al. Definitions, criteria, and global classification of mast cell disorders with special reference to mast cell activation syndromes: a consensus proposal. Int Arch Allergy Immunol 2012;157:215-25.

10. Akin C. Mast cell activation syndromes. J Allergy Clin Immunol 2017;140:349-55.

11. Molderings GJ, Haenisch B, Bogdanow M, Fimmers R, Nöthen MM. Familial occurrence of systemic mast cell activation disease. PLoS One 2013;8:e76241.

12. Afrin LB, Self S, Menk J, Lazarchick J. Characterization of mast cell activation syndrome. Am J Med Sci 2017;353:207-15.

13. Afrin LB. Polycythemia from mast cell activation syndrome: lessons learned. Am J Med Sci 2011;342:44-9.

14. Afrin L. Presentation, diagnosis, and management of mast cell activation syndrome. In: Murray D, editor. Mast cells: phenotypic features, biological functions, and role in immunity. Happauge, NY: Nova Science Publishers, 2013:155-231.

15. Molderings GJ, Kolck UW, Scheurlen C, Brüss M, Homann J, Von Kügelgen I. Multiple novel alterations in Kit tyrosine kinase in patients with gastrointestinally pronounced systemic mast cell activation disorder. Scand J Gastroenterol 2007;42:1045-53.

16. Molderings GJ, Meis K, Kolck UW, Homann J, Frieling T. Comparative analysis of mutation of tyrosine kinase Kit in mast cells from patients with systemic mast cell activation syndrome and healthy subjects. Immunogenetics 2010;62:721-7.

17. Altmüller J, Haenisch B, Kawalia A, Menzen M, Nöthen MM, Fier $\mathrm{H}$, et al. Mutational profiling in the peripheral blood leukocytes of patients with systemic mast cell activation syndrome using next-generation sequencing. Immunogenetics 2017;69:359-69.

18. Berezowska S, Flaig MJ, Ruëff F, Walz C, Haferlach T, Krokowski $M$, et al. Adult-onset mastocytosis in the skin is highly suggestive of systemic mastocytosis. Modern Pathol 2014;27:19-29.

19. Theoharides TC, Valent P, Akin C. Mast cells, mastocytosis, and related disorders. N Engl J Med 2015;373:163-72.

20. Afrin LB, Butterfield JH, Raithel M, Molderings GJ. Often seen, rarely recognized: mast cell activation disease - a guide to diagnosis and therapeutic options. Ann Med 2016;48: 190-201.

21. Molderings GJ, Zienkiewicz T, Homann J, Menzen M, Afrin LB. Risk of solid cancer in patients with mast cell activation syndrome: results from Germany and USA. F1000Res 2017;6:1889.

22. Valent P, Akin C, Bonadonna P, Hartmann K, Brockow K, Niedoszytko M, et al. Proposed diagnostic algorithm for patients with suspected mast cell activation syndrome. J Allergy Clin Immunol Pract 2019;7:1125-33.e1.
23. Weiler CR. Mast cell activation syndrome: tools for diagnosis and differential diagnosis. J Allergy Clin Immunol Pract 2020;8:498-506.

24. Weiler CR, Austen KF, Akin C, Barkoff MS, Bernstein JA, Bonadonna P, et al. AAAAI Mast Cell Disorders Committee Work Group report: mast cell activation syndrome (MCAS) diagnosis and management. J Allergy Clin Immunol 2019;144:883-96.

25. Sabato V, Van De Vijver E, Hagendorens M, Vrelust I, Reyniers E, Fransen E, et al. Familial hypertryptasemia with associated mast cell activation syndrome. J Allergy Clin Immunol 2014;134: 1448-50.e3.

26. Lyons JJ, Yu X, Hughes JD, Le QT, Jamil A, Bai Y, et al. Elevated basal serum tryptase identifies a multisystem disorder associated with increased TPSAB1 copy number. Nat Genet 2016;48:1564-9.

27. Lyons JJ. Hereditary alpha tryptasemia: genotyping and associated clinical features. Immunol Allergy Clin North Am 2018;38:483-5.

28. Sabato V, Chovanec J, Faber M, Milner JD, Ebo D, Lyons JJ. First identification of an inherited TPSAB1 quintuplication in a patient with clonal mast cell disease. J Clin Immunol 2018;38:457-9.

29. Jennings SV, Slee VM, Zack RM, Verstovsek S, George TI, Shi H, et al. Patient perceptions in mast cell disorders. Immunol Allergy Clin North Am 2018;38:505-25.

30. Le QT, Lyons JJ, Naranjo AN, Olivera A, Lazarus RA, Metcalfe DD, et al. Impact of naturally forming human $\alpha / \beta$-tryptase heterotetramers in the pathogenesis of hereditary $\alpha$-tryptasemia. J Exp Med 2019;216:2348-61.

31. Weinstock LB, Brook JB, Myers TL, Goodman B. Successful treatment of postural orthostatic tachycardia and mast cell activation syndromes using naltrexone, immunoglobulin and antibiotic treatment. BMJ Case Rep 2018:2018. pii: bcr-2017-221405. Available at: https://casereports.bmj.com/content/2018/bcr-2017-221405.

32. Afrin LB, Dempsey TT, Rosenthal L, Dorff SR. Successful mast-cell-targeted treatment of chronic dyspareunia, vaginitis, and dysfunctional uterine bleeding. J Obstet Gynaecol 2019;39:664-9.

33. Weinstock LB, Walter AS, Kaleem Z, Brook JB, Afrin LB, Molderings $\mathrm{GJ}$. Restless legs syndrome is associated with mast cell activation syndrome. J Clinical Sleep Med 2020. DOI: 10.5664/ jcsm.8216 [Epub ahead of print].

34. Afrin LB. Mast cell activation disease and the modern epidemic of chronic inflammatory disease. Transl Res 2016;174:33-59.

35. Seneviratne SL, Maitland A, Afrin L. Mast cell disorders in Ehlers-Danlos syndrome. Am J Med Genet C Semin Med Genet 2017;175:226-36.

36. Valent P, Akin C. Doctor, I think I am suffering from MCAS: differential diagnosis and separating facts from fiction. J Allergy Clin Immunol Pract 2019;7:1109-14.

37. Prescott SL, Pawankar R, Allen KJ, Campbell DE, Sinn JK, Fiocchi A, et al. A global survey of changing patterns of food allergy burden in children. World Allergy Organ J 2013;6:21.

38. Moonesinghe H, Kilburn S, Mackenzie H, Venter C, Lee K, Dean T. The prevalence of "novel" food allergens worldwide: a systematic review. Clin Transl Allergy 2015;5(Suppl 3):P9.

39. Dunlop JH, Keet CA. Epidemiology of food allergy. Immunol Allergy Clin North Am 2018;38:13-25.

40. Bergmann KC, Heinrich J, Niemann H. Current status of allergy prevalence in Germany: position paper of the Environmental Medicine Commission of the Robert Koch Institute. Allergo J Int 2016;25:6-10. 
41. Inam M, Shafique RH, Roohi N, Irfan M, Abbas S, Ismail M. Prevalence of sensitization to food allergens and challenge proven food allergy in patients visiting allergy centers in Rawalpindi and Islamabad, Pakistan. SpringerPlus 2016;5:1330.

42. Tham EH, Leung DY. How different parts of the world provide new insights into food allergy. Allergy Asthma Immunol Res 2018;10:290-9.

43. Dalstra JA, Kunst AE, Borrell C, Breeze E, Cambois E, Costa G, et al. Socioeconomic differences in the prevalence of common chronic diseases: an overview of eight European countries. Int J Epidemiol 2005;34:316-26.

44. Haenisch B, Nöthen MM, Molderings GJ. Systemic mast cell activation disease: the role of molecular genetic alterations in pathogenesis, heritability and diagnostics. Immunology 2012;137:197-205.

45. Molderings $\mathrm{GJ}$. The genetic basis of mast cell activation disease - looking through a glass darkly. Crit Rev Oncol Hematol 2015;93:75-89.

46. Anderson G, Horvath J. The growing burden of chronic disease in America. Public Health Rep 2004;119:263-70.

47. Lerner A, Jeremias $P$, Matthias T. The world incidence and prevalence of autoimmune diseases is increasing. Int J Celiac Dis 2015;3:151-5.

48. Newman-Toker DE, Schaffer AC, Yu-Moe CW, Nassery N, Saber Tehrani AS, Clemens GD, et al. Serious misdiagnosisrelated harms in malpractice claims: the "Big Three"-vascular events, infections, and cancers. Diagnosis (Berl) 2019;6: 227-40.

49. Heffler E, Pizzimenti S, Guida G, Bucca C, Rolla G. Prevalence of over-/misdiagnosis of asthma in patients referred to an allergy clinic. J Asthma 2015;52:931-4.

50. Oto MM. The misdiagnosis of epilepsy: appraising risks and managing uncertainty. Seizure 2017;44:143-6.

51. Casas Herrera A, Montes de Oca M, López Varela MV, Aguirre C, Schiavi E, Jardim JR, et al. COPD underdiagnosis and misdiagnosis in a high-risk primary care population in four latin American countries. A key to enhance disease diagnosis: the PUMA study. PLoS One 2016;11:e0152266.

52. Häuser W, Sarzi-Puttini P, Fitzcharles MA. Fibromyalgia syndrome: under-, over- and misdiagnosis. Clin Exp Rheumatol 2019;37 Suppl 116:90-7.

53. Afrin LB, Molderings GJ. A concise, practical guide to diagnostic assessment for mast cell activation disease. World J Hematol 2014;3:1-17.

54. Theoharides TC, Stewart JM, Panagiotidou S, Melamed I. Mast cells, brain inflammation and autism. Eur J Pharmacol 2016;778:96-102.

55. Van Nassauw L, Adriaensen D, Timmermans JP. The bidirectional communication between neurons and mast cells within the gastrointestinal tract. Auton Neurosci 2007;133:91-103.

56. Pace LA. Etiology and clinical presentation of gastroparesis. In: Ibele A, Gould J, editors. Gastroparesis. Cham: Springer, 2020:21-31. DOI: 10.1007/978-3-030-28929-4, ISBN: 978-3030-28929-4.

57. Malagelada C, Karunaratne TB, Accarino A, Cogliandro RF, Landolfi S, Gori A, et al. Comparison between small bowel manometric patterns and full-thickness biopsy histopathology in severe intestinal dysmotility. Neurogastroenterol Motil 2018;30:e13219.
58. Vysniauskaite M, Hertfelder HJ, Oldenburg J, Dreßen P, Brettner $\mathrm{S}$, Homann J, et al. Determination of plasma heparin level improves identification of systemic mast cell activation disease. PLoS One 2015;10:e0124912.

59. Tsuchiya S, Tachida Y, Segi-Nishida E, Okuno Y, Tamba S, Tsujimoto G, et al. Characterization of gene expression profiles for different types of mast cells pooled from mouse stomach subregions by an RNA amplification method. BMC Genomics 2009;10:35.

60. Aung G, Niyonsaba F, Ushio H, Kajiwara N, Saito H, Ikeda S, et al. Catestatin, a neuroendocrine antimicrobial peptide, induces human mast cell migration, degranulation and production of cytokines and chemokines. Immunology 2011;132:527-39.

61. Meyers CD, Liu P, Kamanna VS, Kashyap ML. Nicotinic acid induces secretion of prostaglandin $D_{2}$ in human macrophages: an in vitro model of the niacin flush. Atherosclerosis 2007;192:253-8.

62. Hsueh W. Prostaglandin biosynthesis in pulmonary macrophages. Am J Pathol 1979;97:137-48.

63. Decker K. Biologically active products of stimulated liver macrophages (Kupffer cells). Eur J Biochem 1990;192:245-61.

64. Kuiper J, Zijlstra FJ, Kamps JA, van Berkel TJ. Identification of prostaglandin $D_{2}$ as the major eicosanoid from liver endothelial and Kupffer cells. Biochim Biophys Acta Lipids Lipid Metab 1988;959:143-52.

65. Maciejewski-Lenoir D, Richman JG, Hakak Y, Gaidarov I, Behan DP, Connolly DT. Langerhans cells release prostaglandin $D_{2}$ in response to nicotinic acid. J Invest Derm 2006;126:2637-46.

66. Ali M, Cerskus AL, Zamecnik J, McDonald JW. Synthesis of prostaglandin $\mathrm{D}_{2}$ and thromboxane $\mathrm{B}_{2}$ by human platelets. Thromb Res 1977;11:485-96.

67. Tanaka K, Ogawa K, Sugamura K, Nakamura M, Takano S, Nagata K. Cutting edge: differential production of prostaglandin $D_{2}$ by human helper T cell subsets. J Immunol 2000;164:2277-80.

68. Gallant MA, Samadfam R, Hackett JA, Antoniou J, Parent J-L, de Brum-Fernandes AJ. Production of prostaglandin $D_{2}$ by human osteoblasts and modulation of osteoprotegerin, RANKL, and cellular migration by DP and CRTH2 receptors. J Bone Mineral Res 2005;20:672-81.

69. Jowsey IR, Murdock PR, Moore GB, Murphy GJ, Smith SA, Hayes JD. Prostaglandin $D_{2}$ synthase enzymes and PPAR $\gamma$ are co-expressed in mouse 3T3-L1 adipocytes and human tissues. Prostaglandins Other Lipid Mediat 2003;70:267-84.

70. Bochenek G, Niżankowska E, Gielicz A, Świerczyńska M, Szczeklik A. Plasma $9 \alpha, 11 \beta-\mathrm{PGF}_{2}$, a $\mathrm{PGD}_{2}$ metabolite, as a sensitive marker of mast cell activation by allergen in bronchial asthma. Thorax 2004;59:459-64.

71. Dahlén S-E, Kumlin M. Monitoring mast cell activation by prostaglandin $D_{2}$ in vivo. Thorax 2004;59:453-55.

72. Watanabe K, Iguchi Y, Iguchi S, Arai Y, Hayaishi O, Roberts 2nd LJ. Stereospecific conversion of prostaglandin D2 to $(5 Z, 13 \mathrm{E})$ (15S)-9 alpha-11 beta,15-trihydroxyprosta-5,13-dien-1-oic acid (9 alpha, 11 beta-prostaglandin $\mathrm{F} 2$ ) and of prostaglandin $\mathrm{H} 2$ to prostaglandin F2 alpha by bovine lung prostaglandin F synthase. Proc Natl Acad Sci U S A 1986;83:1583-7.

73. Coquenlorge S, Van Landeghem L, Jaulin J, Cenac N, Vergnolle $\mathrm{N}$, Duchalais E, et al. The arachidonic acid metabolite $11 \beta$-ProstaglandinF2 $\alpha$ controls intestinal epithelial healing: deficiency in patients with Crohn's disease. Sci Rep 2016;6:25203.

74. Dozier BL, Watanabe K, Duffy DM. Two pathways for prostaglandin F2 alpha synthesis by the primate periovulatory follicle. Reproduction 2008;136:53-63. 
75. Morimoto K, Shirata N, Taketomi Y, Tsuchiya S, Segi-Nishida E, Inazumi T, et al. Prostaglandin E2-EP3 signaling induces inflammatory swelling by mast cell activation. J Immunol 2014;192:1130-7.

76. Tsuge K, Inazumi T, Shimamoto A, Sugimoto Y. Molecular mechanisms underlying prostaglandin E2-exacerbated inflammation and immune diseases. Int Immunol 2019;31:597-606.

77. Kawahara K, Hohjoh H, Inazumi T, Tsuchiya S, Sugimoto Y. Prostaglandin E2-induced inflammation: relevance of prostaglandin E receptors. Biochim Biophys Acta 2015;1851:414-21.

78. Ugajin T, Satoh T, Kanamori T, Aritake K, Urade Y, Yokozeki H. FcعRI, but not Fc $\gamma R$, signals induce prostaglandin D2 and E2 production from basophils. Am J Pathol 2011;179:775-82.

79. Båge T, Kats A, Lopez BS, Morgan G, Nilsson G, Burt I, et al. Expression of prostaglandin $E$ synthases in periodontitis: immunolocalization and cellular regulation. Am J Pathol 2011;178:1676-88.

80. Theoharides TC, Tsilioni I, Ren H. Recent advances in our understanding of mast cell activation - or should it be mast cell mediator disorders? Expert Rev Clin Immunol 2019;15:639-56.

81. O'Mahony L, Akdis M, Akdis CA. Regulation of the immune response and inflammation by histamine and histamine receptors. J Allergy Clin Immunol 2011;128:1153-62.

82. Beaven MA. Histamine: its role in physiological and pathological processes. Monogr Allergy 1978;13:1-113.

83. Stephan V, Zimmermann A, Kühr J, Urbanek R. Determination of $\mathrm{N}$-methylhistamine in urine as an indicator of histamine release in immediate allergic reactions. J Allergy Clin Immunol 1990;86(6 Pt 1):862-8.

84. Taracanova A, Tsilioni I, Conti P, Norwitz ER, Leeman SE, Theoharides TC. Substance $P$ and IL-33 administered together stimulate a marked secretion of IL-1 $\beta$ from human mast cells, inhibited by methoxyluteolin. Proc Natl Acad Sci U S A 2018;115:E9381-90.

85. Theoharides TC, Leeman SE. Effect of IL-33 on de novo synthesized mediators from human mast cells. J Allergy Clin Immunol 2019;143:451.
86. Molderings GJ, Haenisch B, Brettner S, Homann J, Menzen M, Dumoulin FL, et al. Pharmacological treatment options for mast cell activation disease. Naunyn Schmiedebergs Arch Pharmacol 2016;389:671-94.

87. Stone KD, Prussin C, Metcalfe DD. IgE, mast cells, basophils, and eosinophils. J Allergy Clin Immunol 2010;125(2 Suppl 2):S73-80.

88. Schliemann S, Seyfarth F, Hipler UC, Elsner P. Impact of age and heterophilic interference on the basal serum tryptase, a risk indication for anaphylaxis, in 1,092 dermatology patients. Acta Derm Venereol 2012;92:484-9.

89. Crivellato E, Ribatti D. The mast cell: an evolutionary perspective. Biol Rev Camb Philos Soc 2010;85:347-60.

90. Aringer M, Costenbader K, Daikh D, Brinks R, Mosca M, RamseyGoldman R, et al. 2019 European League Against Rheumatism/ American College of Rheumatology classification criteria for systemic lupus erythematosus. Arthritis Rheumatol 2019;71: 1400-12.

91. Weinstock L, Brook J, Kaleem Z, Afrin L, Molderings G. Small intestinal bacterial overgrowth is common in mast cell activation syndrome. Am J Gastroenterol 2019;114:S670, abs. 1194.

92. Horny H-P, Akin C, Arber DA, Peterson LC, Tefferi A, Metcalfe DD, et al. In: Swerdlow SH, Campo E, Harris NL, Jaffe ES, Pileri SA, Stein $\mathrm{H}$, et al., editors. WHO classification of tumours of haematopoietic and lymphoid tissues. Lyon, Frankreich: IARC Press, 2017. https://publications.iarc.fr/Book-And-Report-Series/ Who-larc-Classification-Of-Tumours/Who-Classification-OfTumours-Of-Haematopoietic-And-Lymphoid-Tissues-2017, accessed January 5, 2020.

Supplementary Material: The online version of this article offers supplementary material (https://doi.org/10.1515/dx-2020-0005). 